\title{
Posttrial REM sleep: A critical period for consolidation of shiuttlebox avoidance
}

\author{
CHESTER A. PEARLMAN, JR. and RAMON GREENBERG \\ Boston V'A Hospital, Boston, Massachusetts 02130
}

\begin{abstract}
Deprivation of REM sleep for $2 \mathrm{~h}$ immediately following shuttlebox avcidance training produced deficient retention at $24 \mathrm{~h}$ after initial training. REM deprivation beginning $2 \mathrm{~h}$ after training had no effect. REM sleep appears to be involved in consolidation of this learning.
\end{abstract}

Despite extensive research, the function of stage REM sleep remains uncertain. Most promising hypotheses have withered for lack of data (Hennevin \& Leconte, 1971). The idea that stage REM is involved in consolidation of long-term memory, however, has gradually accumulated supporting evidence (Greenberg, 1970: Fishbein, McGaugh, \& Swarz, 1971; Pearlman, 1971). Leconte and Bloch (1970) found that deprivation of REM sleep (REMD) for 2 days after training produced markedly deficient retention of an incompletely learned shuttlebox avoidance response. We replicated this observation using only 1 day of REMD followed by a day for recovery. The recovery period allowed subsidence of nonspecific effects of the REMD procedure (stress, fatigue, and confinement) before retention testing. In both these studies, learning following the retention test was normal. Thus, the deficit could not be ascribed to impaired learning ability. Leconte and Hennevin (1971) made EEG recordings of rats following this avoidance procedure. The animals usually fell asleep soon and showed increased stage REM during the first $3 \mathrm{~h}$ following training. Hennevin, Leconte, and Bloch (1971) subsequently reported that the increase in stage REM was specifically related to acquisition of the avoidance response. As performance reached a plateau after a few days of training, the posttrial increase in REM sleep no longer occurred. These findings suggested a critical period for stage REM and consolidation in this situation.

The present study was designed to investigate the effect of REMD during those first few hours following learning. Since only a brief period of REMD was involved, the animals had ample time to recover completely before retention testing. Because of the limitations of all REMD procedures, we used three different methods whose principal common element was REMD. Thus, a finding of impaired retention with REMD immediately after training would strongly implicate stage REM in the consolidation of this learning.

\section{METHOD}

The Ss were female Wistar rats, about 3 months old. The apparatus was a Lehigh Valley Electronics shuttlebox with a 5-cm barrier.

Each animal had four consecutive series of 10 training trials. Each series was preceded by 5 min of rest in the box. Training followed the conventional delayed conditioning procedure in which both CS and US are response terminated. A 5-sec sonalert as CS preceded a .3-mA shock as US. The intertrial interval was variable, with an average of $1 \mathrm{~min}$. Pilot work had shown an average of about $65 \%$ avoidance on the fourth series with this procedure. Fifty animals with at least two avoidances on the fourth series were divided into five groups roughly equated for percentage avoidance on these 10 trials. Three groups had REMD immediately after the training procedure by different methods: Group 1 Ss were placed on inverted flower pots, $7 \mathrm{~cm}$ in diam. surrounded by water for $2 \mathrm{~h}$. and then returned to their home cages. Group 2 received IP injections of imipramine, $5 \mathrm{mg} / \mathrm{kg}$. and Group 3 received IP injections of pentobarbital, $35 \mathrm{mg} / \mathrm{kg}$. EEG recordings of other animals showed that these REMD procedures were reasonably specific. Animals on the pots averaged $4 \mathrm{~min}$ of non-REM (NREM) sleep during the $2 \mathrm{~h}$ with no stage REM. Animals given imipramine averaged $46 \mathrm{~min}$ of NREM sleep during the first $2 \mathrm{~h}$ after injection with $0.5 \mathrm{~min}$ of stage REM, and animals receiving pentobarbital averaged $117 \mathrm{~min}$ of NREM sleep during the first $2 \mathrm{~h}$ with no stage REM. Baseline recordings at this time of day (between 10:00 a.m. and 4:00 p.m.) averaged $65 \mathrm{~min}$ of NREM sleep per 2-h period with $14 \mathrm{~min}$ of stage REM. The total amount of stage REM per $24 \mathrm{~h}$ was not significantly altered by the pot and imipramine REMD. Normal animals averaged $104 \mathrm{~min}$. pot animals averaged $90 \mathrm{~min}$, and imipramine animals averaged $102 \mathrm{~min}$. Pentobarbital animals averaged considerably less $(45 \mathrm{~min}$ ). The remaining two groups served as controls. Group $4 \mathrm{Ss}$ rested in their cages for $2 \mathrm{~h}$ after training, then had $2 \mathrm{~h}$ of REMD by the pot, and then were returned to their cages. Group 5 had normal sleep following training. Twenty-four hours after training, all animals had 10 retention trials that were identical to the initial trials.

\section{RESULTS}

A measure of percentage change in retention was calculated for each rat from the difference between avoidance on the firal 10 training trials and avoidance on the retention trials divided by avoidance on the final 
Table 1

Mean Avoidance on Final 10 Training Trials and 10 Retention Trials, and Mean Percentage Retention Change*

\begin{tabular}{|c|c|c|c|c|c|}
\hline & $\begin{array}{l}\text { Group 1 } \\
\text { Immediate } \\
\text { REMD } \\
\text { by Pot }\end{array}$ & $\begin{array}{c}\text { Group } 2 \\
\text { REIID by } \\
\text { Imipramine }\end{array}$ & $\begin{array}{c}\text { Group } 3 \\
\text { REMID by } \\
\text { Pentobarbital }\end{array}$ & $\begin{array}{c}\text { Group } 4 \\
\text { REMD } \\
\text { After } 2 \mathrm{H} \\
\end{array}$ & $\begin{array}{l}\text { Group } 5 \\
\text { No REMID }\end{array}$ \\
\hline Training Trials & $\begin{array}{c}6.7 \\
(3-10)\end{array}$ & $\begin{array}{c}6.8 \\
(4-10)\end{array}$ & $\begin{array}{c}7.1 \\
(3-10)\end{array}$ & $\begin{array}{c}6.7 \\
(2-10)\end{array}$ & $\begin{array}{c}6.6 \\
(4-9)\end{array}$ \\
\hline Retention Trials & $\begin{array}{c}1.4^{*} \\
(0-4)\end{array}$ & $\begin{array}{c}1.8^{*} \\
(0 \cdot 8)\end{array}$ & $\begin{array}{c}0.8^{*} \\
(0-3)\end{array}$ & $\begin{array}{l}5.0 \\
(2-9)\end{array}$ & $\begin{array}{c}4.9 \\
(3 \cdot 7)\end{array}$ \\
\hline $\begin{array}{l}\text { Mean Percentage } \\
\text { Retention Change }\end{array}$ & $\begin{array}{l}-77 c^{*} \div \\
(-100-0)\end{array}$ & $\begin{array}{c}-80 \% * \div \\
(-100--20)\end{array}$ & $\begin{array}{c}-86 \%^{* \div} \\
(-100 \cdot-33)\end{array}$ & $\begin{array}{c}-23 \% \dot{\dagger} \\
(-70-+50)\end{array}$ & $\begin{array}{l}-23 \% \dot{\mathrm{i}} \\
(-67 \cdot 0)\end{array}$ \\
\hline
\end{tabular}

-Differs from Groups 4 and $5(p<.01) \quad+$-refers to poorer performance on retention trials, + refers to improled performance

iraining trials. Mean values for the five groups appear in the table. The U test showed that Control Groups 4 and 5 had about the same percentage retention change and both were significantly superior to the REMD Groups 1 , 2 . and $3(\mathrm{p}<.01)$.

\section{DISCUSSION}

Deprivation of REM sleep for $2 \mathrm{~h}$ immediately following shut lebox avoidance training caused a marked retention deficit. The previously mentioned nonspecific effects of the pot REMD procedure seemed negligible in this situation. These factors should have influenced Group 4 more than Group l because the REMD occurred closer to the retention test. One might wonder if the retention deficit in Group 1 resulted from retroactive interference due to sleep loss during the critical period. This interpretation would be hard to reconcile with the fact that Group 3 slept throughout the critical period. Similarly, the retention deficit in Groups 2 and 3 might be ascribed to a nonspecific drug effect. Except for their influence on the REM mechanism, however, pentobarbital and imipramine are, in general, pharmacologic antagonists. Finally, postulation of retroactive interference due to the stress of pot confinement could not account for the results in Groups 2 and 3, which had no confinement. Thus, it seems parsimonious to conclude that REMD is the critical variable in the retention deficit.

These findings suggest that the deficient retention of shuttlebox avoidance observed at $1-2 \mathrm{~h}$ following training (the Kamin effect; cf. Brush, 1970) might result from disruption of the REM-consolidation mechanism by the retention test. We are investigating this possibility.

These results also have implications for other studies of consolidation. Conventional methods for producing retrograde amnesia such as ECS, barbiturate anesthesia, and spreading cortical depression disturb REM sleep during the hypothetical critical period following training (Cohen \& Dement, 1966; Weiss, Roldan, Bohdanecky, \& Fifkova, 1964). Other amnesic agents probably have a similar effect. The influence of REMD on retention varies widely in different species and situations. Thus, this factor could be one source of the confusing discrepancies in results of consolidation studies.

As discussed by Bolles (1970), shut tlebox avoidance, which involves return to a place associated with aversive stimuli, is difficult for the rat. Such learning requires integration of instinctive defense reactions (freezing and fleeing) with environmental feedback of the consequences of behavior. This complexity of the shuttlebox task might account for its vulnerability to REMD, whereas retention of simpler conditioned avoidance is unaffected (Joy \& Prinz, 1969). In humans. habituation to repeated viewing of a frightening film is impaired by REMD (Greenberg, Pillard, \& Pearlman, 1972), whereas tasks requiring no emotional adaptation are unaffected (Grieser, Greenberg, \& Harrison, in press). Thus, the function of stage REM sleep may involve integration of new information into existing structures as described by Breger, Hunter, and Lane (1971).

\section{REFERENCES}

Bolles, R. C. Species-specific defense reactions and avoidance learning. Psychological Review, 1970. 77, 32-48.

Breger, L., Hunter, I., \& Lane, R. W. The effect of stress on dreams. Psychological Issues, 1971, 7(3, Whole No. 27).

Brush, F. R. Retention of aversively motivated behavior. In F. R. Brush (Ed.), Aversive conditioning and learning. New York: Academic Press, 1970. Pp. 401-465.

Cohen, H., \& Dement, W. Sleep: Suppression of REM phase in the cat after ECS. Science, 1966, 154, 396-398.

Fishbein, W., McGaugh, J. L., \& Swarz, J. R. Retrograde amnesia: Electroconvulsive shock effects after termination of rapid eye movement sleep deprivation. Science, 1971, 172, 80-82.

Greenberg, R. Dreaming and memory. International Psychiatry Clinics, 1970, 7, Part 2, 258-267.

Greenberg, R., Pillard, R., \& Pearlman, C. The effect of dream (stage REM) deprivation on adaptation to stress. Psychosomatic Medicine, 1972, 34, 257-262.

Grieser, C., Greenberg, R., \& Harrison, R. The adaptive function of sleep: The differential effects of sleep and dreaming on recall. Journal of Abnormal Psychology, in press.

Hennevin, E., \& Leconte, P. La fonction du sommeil paradoxal: faits et hypothèses. Année Psychologique, 1971, 2, 489-519.

Hennevin, E., Leconte, P., \& Bloch, V. Effet du niveau d'acquisition sur l'augmentation de la durée du sommeil 
paradoxal consécutive à un conditionnement d'évitement chez le rat. Comptes rendus de l'Académie des Sciences de Paris. 1971, 273, D. 2595-2598.

Joy, R. M., \& Prinz. P. N. The effect of sleep altering environments upon the acquisition and retention of a conditioned avoidance response in the rat. Physiology \& Behavior, 1969, 4, 809-814.

Leconte, P., \& Bloch. V. Déficit de la reténtion d'un conditionnement après privation de sommeil paradoxal chez le rat. Comptes rendus de l'Académie des Sciences de Paris, 1970, 271, D, 226-229.

Leconte, P., \& Hennevin, E. Augmentation de la durée de sommeil paradoxal consécutive à un apprentissage chez le rat. Comptes rendus de l'Académie des Sciences de Paris. 1971. 273. D. 86-88.

Pearlman, C. Laten' learning impaired by REM sleep deprivation. Psychonomic Scicnce. 1971, 25, 135-136.

Weiss, T., Roldan. E., Bohdanecky, Z., \& Fifkova. E. Electroencephalographic signs of anesthesia and sleep during neocortical spreading depression. Electroencephalography \& Clinical Neurophysiology, 1964, 16, 429-437.

(Accepted September 18, 1972.) 